\title{
Acute lung injury following occupational exposure to nitric acid
}

\author{
Ji Hoon Jang ${ }^{1}$, Sung Yeon Hwang ${ }^{2}$, Chi Ryang Chung ${ }^{1,3}$, Gee Young Suh ${ }^{1,4}$, Ryoung-Eun Ko ${ }^{1}$ \\ Departments of ${ }^{1}$ Critical Care Medicine, ${ }^{2}$ Emergency Medicine, and ${ }^{3}$ Medicine, and ${ }^{4}$ Division of Pulmonary and Critical Care Medicine, Department of Medicine, \\ Samsung Medical Center, Sungkyunkwan University School of Medicine, Seoul, Korea
}
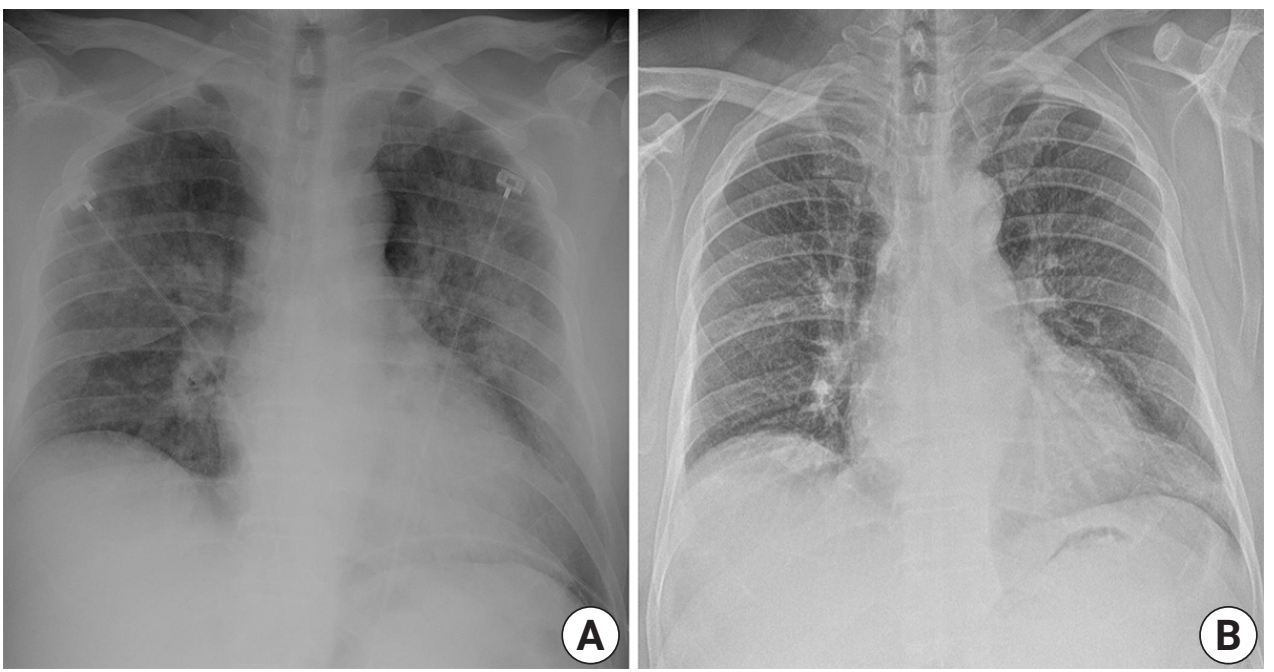

Figure 1. Chest radiograph. (A) Initial chest X-ray demonstrates diffuse bilateral opacities. (B) At hospital discharge, chest $\mathrm{X}$-ray showed marked improvement.

Nitrogen dioxide is one of the compounds formed from breakdown of nitric acid and can lead to extensive damage to the pulmonary epithelium, causing both airway damage and inflammation [1-3]. A 60-year-old male presented to the emergency room complaining of deteriorating productive cough with dyspnea. The patient worked in a metal plating factory and reported 2-minute inhalation of nitric acid approximately 25 hours prior to arrival. At presentation, arterial blood gas analysis showed $\mathrm{pH}$ 7.37, partial pressure of carbon dioxide $41 \mathrm{~mm}$ $\mathrm{Hg}$, and partial pressure of oxygen $59 \mathrm{~mm} \mathrm{Hg}$ on $15 \mathrm{~L} / \mathrm{min}$ of oxygen with a non-rebreathing mask. Crackles were audible over the posterior of both lungs. The chest X-ray showed diffuse bilateral opacities (Figure 1A), and computed tomography presented bilateral peribronchial consolidation and ground glass opacity with sparing in the subpleural region (Figure 2). The patient was treated with high-flow nasal oxygen therapy and transferred to an intensive care unit. Administration of bronchodilator and methylprednisolone $(70 \mathrm{mg} / \mathrm{day}[1 \mathrm{mg} / \mathrm{kg}])$ was initiated. He achieved clinical improvement and was transferred to the general ward with 5 $\mathrm{L} / \mathrm{min}$ via nasal cannula. The patient was discharged 7 days after admission without oxygen

\section{Images in Critical Care}

Received: October 28, 2021

Accepted: November 13, 2021

\author{
Corresponding author \\ Ryoung-Eun Ko \\ Department of Critical Care \\ Medicine, Samsung Medical Center, \\ Sungkyunkwan University School of \\ Medicine, 81 Irwon-ro, Gangnam-gu, \\ Seoul 06351, Korea \\ Tel: +82-2-3410-3429 \\ Fax: +82-2-3410-6956 \\ E-mail: ryoungeun.ko@samsung.com
}

Copyright (C) 2021 The Korean Society of Critical Care Medicine

This is an Open Access article distributed under the terms of Creative Attributions Non-Commercial License (https:// creativecommons.org/li-censes/by-nc/4.0/ which permits unrestricted noncommercial use, distribution, and reproduction in any medium, provided the original work is properly cited. 

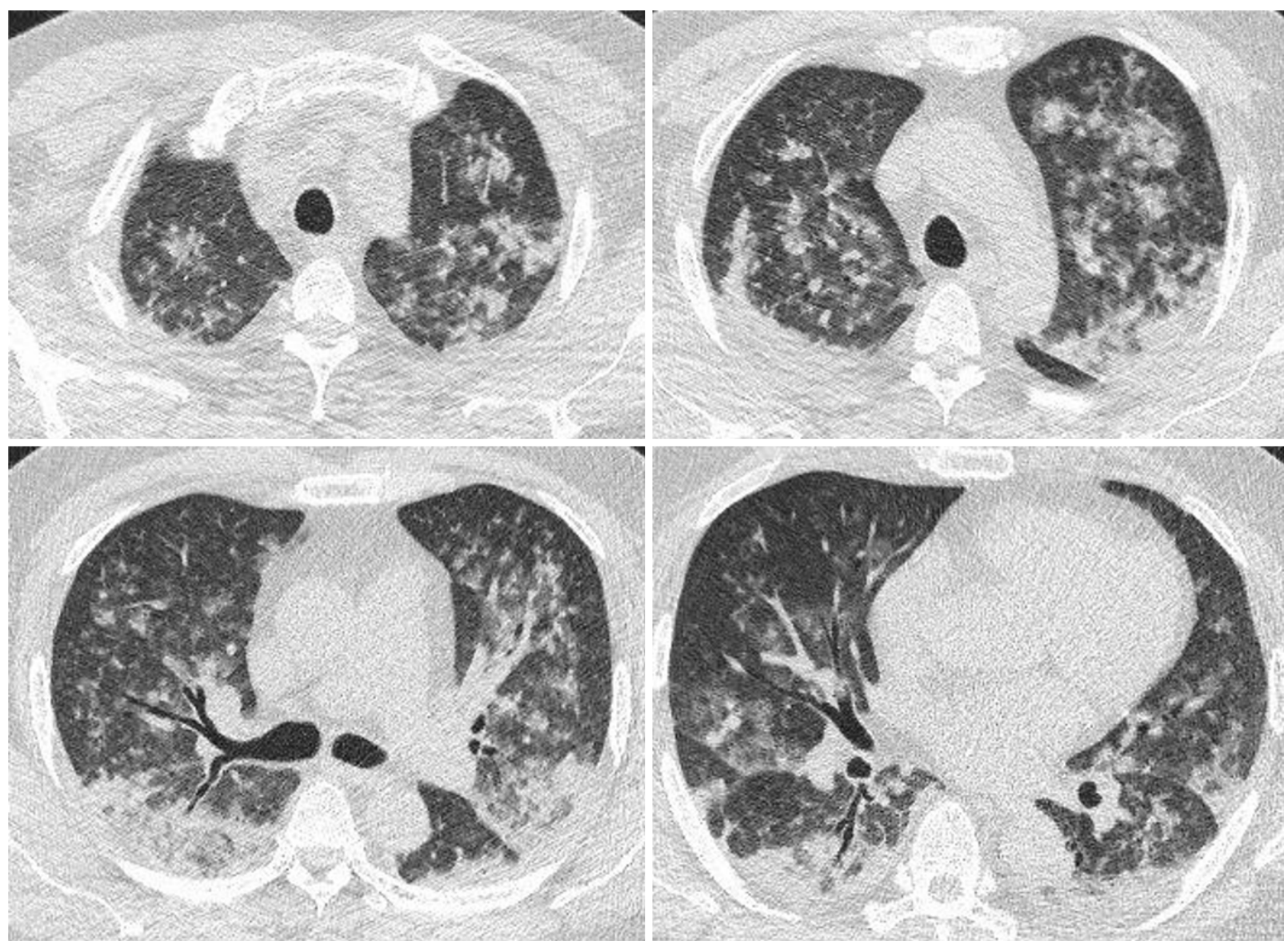

Figure 2. Chest computed tomography scan obtained on the day of emergency room visit presents bilateral peribronchial consolidation and ground glass opacity with sparing in the subpleural region.

therapy (Figure 1B). At discharge, methylprednisolone was reduced to $30 \mathrm{mg} /$ day for 1 week and eventually discontinued after further reduction to $15 \mathrm{mg} /$ day.

\section{CONFLICT OF INTEREST}

No potential conflict of interest relevant to this article was reported.

\section{ORCID}

Ji Hoon Jang Sung Yeon Hwang Chi Ryang Chung Gee Young Suh Ryoung-Eun Ko https://orcid.org/0000-0002-5048-8820 https://orcid.org/0000-0002-1352-3009 https://orcid.org/0000-0003-1830-307X https://orcid.org/0000-0001-5473-1712 https://orcid.org/0000-0003-4945-5623

\section{AUTHOR CONTRIBUTIONS}

Conceptualization: JHJ, REK. Data curation: JHJ, REK. Visualization: JHJ. Writing-original draft: JHJ, REK. Writing-review \& editing: all authors.

\section{REFERENCES}

1. Persinger RL, Poynter ME, Ckless K, Janssen-Heininger YM. Molecular mechanisms of nitrogen dioxide induced epithelial injury in the lung. Mol Cell Biochem 2002;234-235:71-80.

2. Hajela R, Janigan DT, Landrigan PL, Boudreau SF, Sebastian S. Fatal pulmonary edema due to nitric acid fume inhalation in three pulp-mill workers. Chest 1990;97:487-9.

3. Kao SL, Yap ES, Khoo SM, Lim TK, Mukhopadhyay A, Teo ST. Acute lung injury after inhalation of nitric acid. Eur J Emerg Med 2008;15:348-50. 